which the Angelchik antireflux prosthesis was adopted. The use of this device is contentious; it is our opinion that it should be abandoned. ${ }^{15}$

Some of the reasons for the variable results of the Nissen fundoplication have been outlined by DeMeester et al. ${ }^{16}$ In 100 consecutive cases they performed three technical modifications of the procedure. Increasing the calibre of the oesophageal bougie used at operation from 36 to 60 French gauge reduced the incidence of painful swallowing from $83 \%$ to $39 \%$; shortening the length of fundoplication reduced dysphagia from $21 \%$ to $3 \%$; and dividing the short gastric vessels to achieve further mobilisation of the fundus increased the incidence of complete distal oesophageal sphincter relaxation on swallowing from $31 \%$ to $71 \%$. Clearly there are many variables that contribute to a good clinical result from a Nissen fundoplication. ${ }^{17}$ Both anterior ${ }^{18}$ and posterior $^{17}$ fundoplication when performed alone have been reported to give good symptomatic results with fewer side effects. These modifications have not, however, received general acclaim. We believe that with appropriate patient selection and painstaking surgical technique the Nissen procedure may re-establish acompetent cardia and provide relief of symptoms with an incidence of side effects that should be seen as acceptable given the limitations of existing medical treatment.

Optimising the results of fundoplication seems to be a job for the highly skilled, experienced, and specialised surgeon. ${ }^{16}$ This should not preclude the development of simple and technically reproducible operations based on sound physiological principles.$^{19}$ Endoscopic methods for preventing reflux are appealing but require much development. Doctors will undoubtedly use more omeprazole, and this may reduce the number of antireflux operations in a similar manner to the reduction of peptic ulcer operations that occurred as a result of the introduction of cimetidine a decade ago.

Though it is now appropriate to reappraise the practice of antireflux surgery, surgical correction remains the only feasible long term solution until we are more certain about the adverse effects, if any, of long term administration of potent antisecretory drugs in humans.

Consultant Surgeon,

Manchester Royal Infirmary,

Manchester M13 9WL

T V TAYLOR

Professor of Medicine,

S HOLT

University of South Carolina,

Columbia,

South Carolina 29203,

United States

1 Anonymous. Management of gastro-oesophageal reflux [Editorial]. Lancet 1984;i:1054-5.

2 Havelund T, Laursen LS, Skonb-Kristensen E, et al. Omeprazole and ranitidine in treatment of reflux oesophagitis: double blind controlled trial. $\mathrm{BrMed} \mathcal{f}$ 1988;296:89-92.

3 Ruth M, Embom H, Lundell L, Loelroth H, Sandburg N, Sandmark S. Effect of omeprazole or ranitidine treatment on 24 hour oesophageal acidity in patients with reflux oesophagitis. Scand $\mathcal{J}$ Gastroenterol 1988;23:1141-6.

4 Huttemann W. Cisapride in oesophagitis: A placebo controlled trial. Digestion 1986;34:143.

5 Dent J, Hetzel DJ, Reed WD, Narievala FM, Mitchel BL, McCarthy JH. Healing of peptic oesophagitis with omeprazole. Gastroenterology 1986;90:1392.

6 Hetzel DJ, Dent J, Reed WD, Narievala FM, Mitchel BL, McCarthy JH. Healing and relapse of severe peptic oesophagitis after treatment with omeprazole. Gastroenterology 1988;95:903-12.

7 Hirschowitz BI, Holt S, Robinson MG, et al. Omeprazole is superior to placebo in the complete relief of heartburn and endoscropic healing in patients with reflux oesophagitis. US multicentre relief of heartburn and endoscropic healing in patient
dose-ranging study. Am $\mathcal{F}$ Gastroenterol (in press).

8 Klinkenberg-Khal EC, Jansen JMBJ, Fasten HPM, Menwissen SGM, Lamers CBHW. Doubleblind multicentre comparison of omeprazole and ranitidine in the treatment of reflux oesophagitis. Lancet 1987; i:349-51

9 Sandmark S, Carlsson R, Fausa O, Lindell L. Omeprazole or ranitidine in the treatment of reflux oesophagitis. Results of a double-blind randomised Scandinavian multi-centre study. Scand $\mathcal{F}$ Gastroenterol 1988;23:625-32.

10 Skinner DB. Complications of surgery for gastro-oesophageal reflux. World f Surg 1977;1:485-91.

11 Zucker K, Peskin GW, Said RP. Recurrent hiatal hernia repair. Arch Surg 1982;117:413-21.

12 Negre JB. Postfundoplication symptoms. Ann Surg 1983;146:635-7.

13 Negre JB, Markkula H, Cyrilainen O. Nissen fundoplication: results at 10 year follow up. Am $\mathcal{F}$ Surg 1983;146:635-7.

14 Shirazi SS, Schulze K, Soper RT. Long-term follow-up for treatment of complications of chronic reflux oesophagitis. Arch Surg 1987;122:548-52.

15 Durrans D, Armstrong CP, Taylor TV. The Angelchik anti-reflux prosthesis-some reservations. Brf Surg 1985;72:525-7.

16 DeMeester TR, Bonavina $\mathrm{L}$, Albertucci $M$. Nissen fundoplication for gastro-oesophageal reflux disease. Ann Surg 1986;204:9-20.

17 Guarner V, Martinez N, Gavino JF. Ten year evaluation of posterior fundoplasty in the treatment of gastro-oesophageal reflux. Am $\mathcal{f}$ Surg 1980;139:200-3.

18 Mir J, Ponce J, Juan M, Garrigues V, Ibanez JL, Berengner J. The effect of $180^{\circ}$ anterior fundoplication on gastro-oesophageal reflux. Am $\mathcal{F}$ Gastroenterol 1986;81:172-5.

19 Taylor TV, Knox R, Pullan BR. Vertical gastric plication in the treatment of reflux oesophagitis. Ann R Coll Surg Engl 1989;71:31-6.

\title{
"It isn't epilepsy is it, doctor?"
}

\section{A question expecting, and sometimes deserving, the answer "No"}

Childhood epilepsy is both underdiagnosed and overdiagnosed. The misdiagnosis of non-epileptic events as epilepsy is the commoner error and potentially the more serious. The anxiety audible in a mother's question, "It isn't epilepsy is it, doctor?" shows the depth of negative emotions inherent in the concept of epilepsy. Too many children (and adults) are referred to hospital with a diagnosis of epilepsy or "? epilepsy" without a detailed history of the event being obtained. When this is eventually taken it will often clearly show the diagnosis to be wrong.

A full history must be taken from parents, a teacher, or another "caretaker" who has seen the events that prompted the question, but public awareness of what may occur in an epileptic fit is limited. Distressed parents are poor witnesses to fact. Many, seeing the child's first attack, believe that he or she will die in it. ${ }^{1}$ Their vocabulary may be inadequate to describe the event, which is usually outside their experience. Leading questions are often needed; the informant should be asked not merely to describe but to imitate what occurred. The doctor may need to insist on this before getting the desired response and should be prepared to offer a choice of mimed seizure patterns - for example, infantile spasms or tonic-clonic convulsions-which may help the witness to remember.

The child himself is the only person who knows what he has experienced, and the older child should always be asked about his episode. Young children can, for example, graphically describe vertigo and may have complained during attacks of "the naughty room going round" or rationalised it by saying that a giant was shaking the house. Such a description, which clearly indicates that the child was fully aware at the time, suggests episodes of benign paroxysmal vertigo, ${ }^{23}$ yet such symptoms are often attributed to "petit mal" or some other form of epilepsy. (O'Donohoe rightly believes the term "petit mal" to be perhaps the most misused in the subject. ${ }^{4}$ )

Jeavons found that one fifth of 470 children and adults seen in two epilepsy clinics did not have epilepsy. ${ }^{5}$ Documenting the many disorders misdiagnosed as epilepsy, he emphasised that events before and immediately after an attack are often as important as diagnostic clues as the the episode itself. For example, only the patient can describe the faintness, light headedness, sinking abdominal feeling, and greying of vision 
before losing consciousness that suggest a syncopal attack. The circumstance of its occurrence, often stressful or painful, may strengthen the diagnosis. Recovery is usually quicker and postictal sleep rarer after a faint than after an epileptic fit, though the malaise felt at the start of the attack will often persist for a time after it. Often these important historical clues are neglected, while the occurrence of stiffening, slight clonic movements, or urinary incontinence in a syncopal attack is taken as proof of an epileptic fit. An eye witness account of deathly pallor and an impalpable pulse, if available, is diagnostically helpful.

Situational clues are especially important in breath holding spells of the cyanotic or pallid ("reflex anoxic seizure") types..$^{6-9}$ In cyanotic seizures a child, often a boy with poor tolerance of frustration, suffers a painful stimulus - a fall, a fright, or a frustration - and cries vigorously for one or two breaths and then holds his breath in expiration. He then becomes cyanosed, loses consciousness, and falls limply. A few jerks and brief stiffening may follow; this does not mean that he has epilepsy. The attacks vary greatly in frequency and usually cease by 5 years of age. In the pallid variety the child reacts to a sudden unexpected, mildly unpleasant stimulus, often a slight blow to the back of the head, but sometimes to his first experience of a "grown up" bath, or even a new taste, ${ }^{10}$ with little or no crying followed by apnoea, pallor, limpness, and unresponsiveness. Stiffening, opisthotonos, and convulsive movements may occur. Cardiac asystole for two seconds or more is common, and when it lasts eight seconds or more convulsive movements ensue. Stephenson has described these "white reflex anoxic seizures" in detail and emphasised the need to show the abnormally sensitive occulovagal reflex evoked by ocular compression during combined electrocardiographic and electroencephalographic recording. ${ }^{78}$ Confusion with epilepsy should not occur; true epileptic seizures, though often occurring in emotion situations, are seldom, and never invariably, provoked by such specific stimuli." To label children with such attacks as epileptic is harmful and to prescribe phenobarbitone may be disastrous. In most cases reassurance is sufficient. With frequent and severe attacks treatment with atropine methonitrate is helpful. ${ }^{12}$

Migraine, narcolepsy, night terrors, nightmares, masturbation, "gratification phenomena," and cardiac arrhythmias are other events often mistaken for epilepsy. ${ }^{13}$ A detailed history and a refusal to jump to conclusions should prevent this. When in doubt (and there will always be doubtful cases) the child should be given the benefit of this doubt, while the doctor keeps an open mind and awaits events. More harm usually results from a premature and incorrect diagnosis of epilepsy, "a passport to prejudice" as Taylor has called it, ${ }^{14}$ than from delayed recognition.

Particular difficulty may arise in cases of hysterical pseudoseizures ${ }^{15}$ and of "epilepsy" as a symptom of "Munchausen syndrome by proxy." 1617 Staff in schools for children with epilepsy are familiar with the feigned seizures with which some of their pupils add to their regular fits for various purposes and are skilled at separating the wheat from the chaff. If, however, the child is not a "known epileptic" (a phrase which carries its own dangers) the bizarre behaviour of a child reported by his parent may prove a difficult diagnostic problem for the doctor. Dramatic episodes in which the child responds by struggling harder the more he is restrained ("it took three people to hold him down") are seldom due to epilepsy, though the phase of postictal confusion after a fit may be marked by such behaviour. The study of prolactin secretion may help to distinguish genuine seizures from pseudoseizures. Bye et al found increased serum concentrations of prolactin in eight of 10 children with tonic-clonic seizures and in three of five with complex partial seizures but in none of those with non-epileptic episodes. ${ }^{18}$ They considered that a serial rise in prolactin concentration or a value above $500 \mathrm{mU} / \mathrm{l}$ is evidence that a generalised or complex partial seizure has occurred and recommended serial blood sampling between zero and 10 minutes after a dubious episode and again after 20 minutes.

"Munchausen syndrome by proxy" is that form of child abuse in which a parent, usually the mother and often a nurse, fraudulently fabricates symptoms and signs in a child. ${ }^{16}{ }^{17}$ Vomiting, gastrointestinal bleeding, or haematuria may be complained of. Seven of Meadow's 19 patients had neurological symptoms fabricated by a parent; three presented with "seizures."1617 Like other forms of child abuse this bizarre and dangerous syndrome is increasingly recognised, but to discover the truth in such cases may be extremely difficult. The unsuspecting doctor unwittingly colludes with the mother in harming her child, and successive siblings may be affected. Once the label "known epileptic" is applied the diagnosis is seldom challenged.

In certain epileptic seizures of childhood the evidence of the patient is crucial. In the age group 3 to 14 years many generalised nocturnal convulsions start as simple partial seizures and become generalised secondarily in the syndrome of benign rolandic ("centrotemporal" or "sylvian") epilepsy. ${ }^{19} 20$ Unless the focal onset of the seizure is witnessed it is reported as a generalised convulsion. The vital clue may be given by the child if he is asked. He will often describe the onset of jerking and sensory symptoms on one side of his face, with spread to the ipsilateral arm and leg. The electroencephalogram will usually suggest the diagnosis, showing mid-temporal spike foci that are unilateral or sometimes bilateral. In such cases imaging of the brain gives normal results, the seizures are often limited to sleep and respond well to carbamazepine, and the outlook is good, with attacks often stopping by the age of 14 . Some children will have only one or two seizures, and it has been suggested that drugs may safely be deferred until a third fit has occurred..$^{20}$

In complex partial seizures of the temporal lobe and other origin the older child will describe bizarre disturbances of perception and hallucinations. ${ }^{+} \mathrm{He}$ should be asked and encouraged to do so, as he is sometimes afraid to discuss them, fearing disbelief or that he is going mad. The seizures of juvenile myoclonic epilepsy are often unrecognised until a major convulsion has occurred, as the teenager, confused and worried by his early morning myoclonic jerks, may keep his own counsel or even, if medical advice is sought, may risk being regarded as hysterical. ${ }^{21} 22$

In these and some other syndromes of epilepsy the electroencephalogram can give valuable supporting evidence for the diagnosis, but the basic approach to the important questions: "Is it epilepsy?" "If so, what type of epilepsy?" and "What is the treatment?" should always be clinical.

E M BRETT

Consultant Neurologist,

Hospital for Sick Children,

London WCIN $3 \mathrm{JH}$

1 Rutter N, Metcalfe DH. Febrile convulsions - what do parents do? Br Med f 1978;ii:1345-6.

2 Basser LS. Benign paroxysmal vertigo of childhood. A variety of vestibular neuronitis. Brain 1964;87:141-52.

3 Dunn DV, Snyder H. Benign paroxysmal vertigo of childhood. Am f Dis Child 1976;130: 1099-100.

4 O'Donohoe NV. Epilepsies of childhood. 2nd ed. London: Butterworth, 1985.

5 Jeavons PM. The practical management of epilepsy. Update 1975;1:11-5.

6 Lombroso CT, Lerman P. Breath-holding spells (cyanotic and pallid infantile syncope). Pediatric 1967;39:563-81.

Stephenson JBP. Reflex anoxic seizures ("white breath-holding") non-epileptic vagal attacks. Arch Dis Child 1978;53:193-200.

8 Stephenson JBP. Febrile convulsions and reflex anoxic seizures. In: Rose FC, ed. Reseurch papers in epilepsy. London: Pitman, 1983:244-52.

ic seizure). Arch Dis ( hild 1984;59:1118-9.

10 Sheldon W. Suncopal attacks in infancy. (ireat Ormond Street fournal 1952;3:20-2. 
11 Stores G. Psychological factors and seizure occurrence in children. In: Apley J, Ounsted C, eds. One child. London: Spastics International Medical Publications, William Heinemann Medical Books; Philadelphia: J B Lippincott, 1982:75-83.

$12 \mathrm{McW}$ illiam RC, Stephenson JPBP. Atropine treatment of reflex anoxic seizures. Arch Dis Child 1984;59:473-8.

13 Rutter N, Southall DP. Cardiac arrhythmias misdiagnosed as epilepsy. Arch Dis Child 1985;60:91-4.

14 Taylor DC. Aspects of seizure disorders II. On prejudice. Dev Med Child Neurol 1973;15:91-4

15 Finlayson RE, Lucas AR. Pseudoepileptic seizures in children and adolescence. Mayo Clin Proc 1979;54:83-7.
16 Meadow R. Munchausen syndrome by proxy. Arch Dis Child 1982;59:473-5.

17 Meadow R. Fictitious epilepsy. Lancet 1984; ii: $25-8$.

18 Bye AME, Nunn KP, Wilson J. Prolactin and seizure activity. Arch Dis Child 1985;60:848-51.

19 Beaussart M. Benign epilepsy of childhood with rolandic (centro-temporal) paroxysmal foci: . Benign epilepsy of childhood with roland

20 Ambrosetto G, Giovanard B, Rossi P, Tassinari CA. Predictor factors of seizure frequency and duration of antiepileptic treatment in rolandic epilepsy. Brain Dev 1987;9:300-4.

21 Asconape J, Penry JK. Some clinical and EEG aspects of benign juvenile myoclonic epilepsy. Epilepsia 1984;25:108-14.

22 Clement MJ, Wallace SJ. Juvenile myoclonic epilepsy. Arch Dis Child 1988;63:1049-53.

\section{Perioperative deaths among children}

\section{Standards of care are high, but those who don't care for children regularly shouldn't care for them at all}

Society may be judged by the care it provides for its most dependent members. The decision that the first report of the National Confidential Enquiry into Perioperative Deaths should examine deaths among children aged under 11 within 30 days of surgery is therefore fitting, although it was also influenced by practical considerations. The long term aim of the national inquiry is to review 6000 deaths annually, but the logistic problems persuaded the steering committee initially to select a smaller, more easily defined sample. The resulting report, published this week, is the first time that a single surgical-anaesthetic specialty has been formally assessed in such detail.'

The report's first conclusion, that the overall standard of surgical and anaesthetic care of children is excellent, is therefore a matter for satisfaction. Neonatal and paediatric surgery is a relatively new specialty, and progress in the care of children with both cardiac and non-cardiac conditions to the standards illustrated by the inquiry has also been due to the parallel development of specialist anaesthetic practice. This has played an important part not only in the operating theatre but also preoperatively in clinical assessment and postoperatively in the intensive care unit. Nevertheless, and unsurprisingly, there is room for improvement in both surgery and anaesthesia.

The desirability of children's surgery and anaesthesia being performed by clinicians with a regular paediatric practice is clear-not least to those without such a practice who are forced by circumstances or staff shortages to care for children. The number of full time paediatric surgeons has increased in recent years, and now all teaching hospitals have full time paediatric surgeons (except in one region) and anaesthetists with specialist paediatric experience. But inevitably some work is done by general surgeons, and the report emphasises not only the importance of regular paediatric practice but also the problems posed by some locum staff not having the competence to care for children. The British Association of Paediatric Surgeons has produced guidelines on training for general surgeons who are responsible for children. Some years ago the Royal College of Surgeons of England suggested that in district general hospitals with four or more surgeons one should have had some training in paediatric surgery.

The inquiry underlined the accepted need for continuing postgraduate education for all consultants who care for children-particularly those in district and single specialty hospitals. In practice this probably entails their joining and attending the scientific meetings of specialty associations such as the British Association of Paediatric Surgeons and the Association of Paediatric Anaesthetists of Great Britain and Northern Ireland. General surgeons may not be aware that the
British Association of Paediatric Surgeons would welcome them as members.

Single specialty units pose particular problems, which are likely to be resolved only by an increase in the number of medical and nursing staff trained in caring for children. Care for children could also be improved by a more widespread acceptance of the need for transfer, perhaps between regions, of children with complex surgical problems, notably those with burns or neurosurgical or cardiac conditions.

The report rightly emphasises the value of a team approach to caring for paediatric surgical patients. Training programmes in paediatric medicine should clearly include a period on a surgical unit, just as the training of general surgeons who will care for children should include close contact with paediatricians or paediatric surgeons. Nowhere is this cooperation more important than in the care of a severely injured child.

As in the original survey of perioperative deaths in $1987,{ }^{2}$ this report emphasises the importance of supervision of juniors. Its final recommendation is that no trainee should undertake any anaesthetic or surgical operation on a child of any age without consultation with his or her consultant. But this is a counsel of perfection; with a consultant's workload spread across more than one hospital it may be difficult to achieve. It also fails to acknowledge that many trainees in paediatric surgical and anaesthetic training programmes have reached a high degree of clinical and technical competence, certainly in the less than complex procedures such as routine circumcisions and hernia repairs in fit children.

The report's first recommendation is that the National Enquiry into Perioperative Deaths should continue. Few will disagree, although both this and the 1987 report have probably done as much as is presently possible in encouraging better standards of care. High standards seem at present to be more at risk from deficiencies in resources than from deficiencies in training or supervision or audit programmes. Realisation of all six of the report's recommendations (see p 1608) on ways to improve the surgical care of children will involve not only clinicians but also politicians and managers. If clinical information services are improved-another of the recommendations - then an even more formidable task may lie ahead: the investigation of perioperative morbidity.

MALCOLM H GOUGH

Consultant Surgeon,

John Radcliffe Hospital,

Oxford OX3 9DU 1 National Confidential Inquiry into Perioperative Deaths. Report 1989. London: NCEPOD, 1990.
2 Buck N, Devlin HB, Lunn JN. The report of the confidential enquiry into perioperative deaths. London:
Nuffield Provincial Hospitals Trust/King's Fund, 1987. 